\title{
Research on the Selection of Enterprise of Logistics Outsourcing and Cooperation Partners
}

\author{
Zhao Rong \\ School of Economic and Management \\ Shengyang Aerospace University \\ Shengyang, China \\ zhaorong@126.com
}

\author{
Lian Fenghui \\ Flight Vehicle Control Deparment \\ Aviation University of Air Force \\ Changchun, China \\ 990378945@qq.com
}

\begin{abstract}
With the development of economy, logistics industry has been rapid development in our country, logistics enterprise's service and management level also had the very big enhancement, enterprises gradually realized that the modern logistics has become "the third profit source", is the enterprise to reduce costs and gain a competitive advantage. More and more manufacturing enterprises, sales enterprise to focus resources, save administrative costs, enhance core competitiveness, the business outsourcing, logistics outsourcing has become effective means, the enhancement enterprise core competitive ability has become inevitable trend in today's economic development, the demand for logistics services, logistics outsourcing to reduce operational costs and maintain competitive advantage has important role. While most companies have been deeply aware of the logistics outsourcing is optimizing the allocation of resources and improve the core competitiveness of enterprises effectively works, however, logistics outsourcing in bring economic growth, at the same time also brought new problems for the enterprise, the practice has proved that not all the outsourcing project can succeed. How to correctly and accurately evaluate the logistics outsourcing partners and choose to become one of the important influence factors.At first, this paper analyzes the third party logistics and logistics outsourcing in our country development present situation and development trend of the third party logistics service provider, and then build the evaluation system of enterprise logistics outsourcing partners, and establish the corresponding fuzzy comprehensive evaluation model, for enterprises to choose the logistics outsourcing partners to provide reference and reference.
\end{abstract}

Keywords-Logistics; Logistics outsourcing; Partners; Third party logistics; Fuzzycomprehensive estimation

\section{INTRODUCTION}

With the rapid development of economic globalization and the trend ofinformation networks, the demand for logistics grows and logistics management faces more severe challenges. Now, with the fierce competition in the market and the high input cost for a vertical integration model, fierce international competition and the rapid updating of information technology and other aspects of the social environment, the old modern logistics management has been unable to meet their needs. On the one hand, enterprises need to maintain the unique demands while on the other hand they have to adapt to market development. Therefore, it is almost impossible for a company to keep all the businesses in long-term competitive advantage. In this case, it will become a trend for companies to outsource the business what they are not good at.

In recent years, many enterprises have expanded their needs in logistics outsourcing in order to reduce the cost of production and marketing and improve the core competitiveness of enterprises; while many multinational companies are expanding into Chinamore and more in order to reduce supply chain costs and they are also expanding logistics outsourcing needs. These not only stimulated China's logistics outsourcing market, but also contributed to China's logistics outsourcing market.

\section{OVERVIEW OF LOGISTICS OUTSOURCING}

\section{A. Logistics outsourcing}

To focus on improving the core competitiveness of enterprises, some sales or production enterprises will transfer logistics business of the enterprise to a third party logistics company to operate in the form of contracts--such a long-term, strategic and mutually beneficial cooperation is called logistics outsourcing.

\section{B. Status of logistics outsourcing abroad}

In worldwide, logistics outsourcing in developed European countries have been developing for a long period of time. In recent years, with the development of the globalization of world economy, third-party logistics economy is also undergoing changes. The rapid development of logistics outsourcing with an extraordinary potential and the international logistics outsourcing shows its distinctive features: more extensive logistics outsourcing types; increasing role of information technology in the logistics outsourcing; faster service efficiency; increasingly low cost; third-party logistics enterprises gradually shift to business cooperative partners.

\section{Status of logistics outsourcing domestically}

Domestically, many scholars define logistics outsourcing as the way that enterprises transfer their noncore businesses to the third-party logistics for operation.JiBaoling believes that logistics outsourcing is 
the enterprises who are engaged in the production or sales entrust their logistics business to specialized third-party logistics companies to operatein order to enhance the core competitiveness of enterprises. That is the enterprise to build the core competitiveness through the rational allocation of resources.

Though there are different arguments for logistics outsourcing, there is no difference in essence. The logistics outsourcingwe are talking about is also commonly known as third-party logistics, which can be defined as the production and operation enterprises entrust the logistics activities which should be done by their own to a company specializing in logistics services in the form of contracts, so as to focus resources on the development of core business; meanwhile,they should keep close touch with logistics services companies with network information system to maintain the management and control of the entire process.

\section{LOGISTICS OUTSOURCING AND THE CHOICE OF PARTNERS}

\section{A. Decision-making methods of logistics outsourcing}

Through third-party logistics, companies can achieve the purpose of improving customer service levels and reducing costs. But how to decide whether to use a thirdparty logistics provider requires the enterprises to develop appropriate evaluation criteria.

1) Traditional decision-making methods of logistics outsourcing

Traditional business decisions are based on the presence or absence of the ability to conduct logistics on its own. In order to facilitate the management, if the enterprise has technologies and facilities which can help them to operation on their own, they can operate by self; but if self-supporting is difficult in certain logistics chain, it should be outsourced. When makingdecisions, enterprises usually do not consider the cost and services received and outsourcing means that companies purchase transportation or storage servicesin the professional logistics companies.

2) Modern decision-making methods of logistics outsourcing

The qualitative analysis methods of logistics outsourcing mainly included the following three categories:

Intuitive judgment method, which is based on the data from investigation and sorting and combined with research and analysis, so to effectively audit the suppliers.

Tender method. The company proposes a tender and the suppliers bid for it based on requirements and the company determines to cooperate with which one and reaches agreements and signs the contract with suppliers who propose the most favorable condition.

Negotiation selection method. First, the company would selecta few suppliers with favorable supply conditions and then consult with them separately, and finally decide the most suitable suppliers.

The current quantitative evaluation methods for thirdparty logistics are mainly divided into three categories:

Weight analysis method, which tends to evaluate thirdparty logistics companies from the overall perspective. And due to the subjective characteristics in weighting factor, he gap between the decision results and the actual results is usually great.

Mathematical programming method. If it only considers timely delivery, price, service quality and other quantitative indicators, it is difficult to include qualitative indicators such as financial strength and corporate credit and reputation into the restrictions and goals in planning.

Probabilistic method. Because the decisionmakingresults are directly affected by the object characteristics and period, so the applicable scope would be restrained to a certain degree.

\section{B. The choice of partners in logistics outsourcing}

\section{1) Elements that affect modern logistics outsourcing} decisions

When companies do outsourcing decisions, to whom the outsourcing will be is an important question, which is to say which outsourcing partner will you choose. When companies do outsourcing decisions, to whom the outsourcing will be is an important question, which is to say which outsourcing partner will you choose.

2) Criteria for modern logistics outsourcing decision

Today, the rapid development of information technology makes the relationship between logistics company and customers change; logistics shift from traditional public logistics services to third-party logistics service, while non-logistics enterprises put more emphasis on the highly integration and supply chain management of various functional departments and logistics enterprises and non-logistics enterprises tend to form strategic partnership, which has reduced the risks for cooperation among enterprises. Therefore, accompanied by such changes in the service relationship, decision criteria should make corresponding changes.

Enterprises may adopt the form of logistics outsourcingfor economic purposes or strategic goal, and the main direction of development for logistics outsourcing is determined by its strategic objectives; according to different types of outsourcing, monitoring tools on patrial business are quantified and the monitoring model is mature, but in terms of business, the enterprises have to maintain good relations with them in order to stimulate the initiatives ofsubcontractors; moreover, the dependency of companies on subcontractors determines who is more advantageous between the two, if an enterprise is much dependent on subcontractors, they should try to offer the service resources for subcontractors as much as possible. When consideringwhether outsourcing logistics is necessary not, the following three perspectives should be considered: the first is whether it is consistent with the business development strategy; the second is whether the enterprises'comprehensive strength is threatened; and the third is whether the economic profits of logistics can increase.

\section{Evaluation of enterprise logistics outsourcing partners}

To make a comprehensive ans systematic evaluation of enterprise logistics outsourcing partnership, it is necessary to establish a complete and scientific evaluation system. The set of evaluation indicators forms the basis of all quantitative analysis and the proper set of evaluation index directly affects the correctness of final evaluation results. 
When creating a comprehensive evaluation index system, in addition tocomplying the basic norms in statistics, the following principles should be followed:

1) Completeness

For the established indicators, it should be able to fully reflect the overall quality of the enterprise. The content and scope of indicators shouldinclude both the demand views of enterprises and views of third party logistics enterprises; both the interrelation and interaction of enterprises with the external business environment and the characteristics of the enterprise itself; both thequantitative indicators and qualitative indicators, etc.

\section{2) Scientific usefulness}

Index system must be established on a scientific basis, the concept must be clear and reflect the actual situation of partners scientifically, being both moderate and practical.

\section{3) Relative independence}

Each indicator should be set up to reflect its unique properties and it should be possible to reduce the compatibility between various indicators

\section{4) Hierarchy}

There are many types of indicators established and in order to meet the needs of completeness, relative independence and scientific principles, the index can be st to be stratified, with several low-level indicators to reflect the high level indicators.

\section{THE APPLICATION OF FUZZY COMPREHENSIVE EVALUATION IN THE CHOICE OF OUTSOURCING PARTNERS}

\section{A. Introduction to fuzzy comprehensive evaluation method}

1) Overview of fuzzy comprehensive evaluation method

Fuzzy comprehensive evaluation method is a combination of evaluation method based on fuzzy math. Transforming qualitative indicators into quantitative indicators according to the theory of fuzzy mathematics membership, is to use fuzzy math to get the overall assessment of subjects or objects that are subject to many factors.

In detail, fuzzy comprehensive evaluation is a method to comprehensively evaluate the membership hierarchy of things from multiple factors based on fuzzy math and by using the principle of fuzzy relation synthesis to handle quantitatively some factors which are difficult to determine the boundaries or quantitatively dispose.

2) Related terms in fuzzy comprehensive evaluation

For the ease of description, the terms and concepts related to fuzzy comprehensive evaluation method will be introduced as follows:

Evaluation factor F: refers to the details of council tenders

Value of evaluation factor FV: refers to the specific value of F. For example, if the economic parameter of a certain bidder is 100, then the bidder's FV is 100 .

The evaluation value $\mathrm{E}$ : the degree of quality of $\mathrm{F}$. The best evaluation factor $\mathrm{E}$ is 1 ; in accordance with suboptimal level, the value of $\mathrm{E}$ is between 0 and 1 , namely, 0 $\leqslant \mathrm{E} \leqslant 1$.

Average rating value EP: refers to the average evaluationof $\mathrm{F}$ by members of the evaluation committee.
EP is equal to the total score by all members of the evaluation committee divided by the total number of judges.

Weight W: refers to the degree of importance and status of the F. The sum of F1 is 1 ; and the sum of the weights $F$ in every next level is also 1 .

The weighted average evaluation value Epw: refers to the EP weighted. Epw $=\mathrm{EP} * \mathrm{~W}$.

Comprehensive evaluation value Ez: the sum of Epw in the same level F. Ez also corresponds to the previous level.

\section{B. Steps to build the fuzzy comprehensive evaluation method}

Fuzzy comprehensive evaluation method is a comprehensive evaluation method based on fuzzy mathematics, which quantifies some of the factors that is not easy to determine the value and boundary to comprehensively evaluate. The advantages of fuzzy comprehensive evaluation method are: the use of AHP makes the system simple and clear; quantitative analysis and qualitative description closely combined better solves the problem that qualitative indicators are difficult to quantify, so it isscientific and reasonable. Here are the steps to build the fuzzy comprehensive evaluation method:

1) Determine the factor domain of evaluationobject

The number of evaluation indexes are $\mathrm{P}$, $\mathrm{C}=\left\{\boldsymbol{C}_{1}, \boldsymbol{C}_{2}, \ldots, \boldsymbol{C}_{m}\right\}$

2) Determine the evaluation ranking domain

$$
u=\left\{u_{1}, u_{2}, \cdots \cdots, u_{p}\right\} \text { is the ranking set. Each rank }
$$
can be corresponded by a fuzzy subset.

\section{3) Construct fuzzy relationship matrix $R$}

After building the ranking fuzzy subset, quantify each factor of evaluated objects one by one $u_{i}(i=1,2, \cdots \cdots, p)$, that is to say, the perspective of a single factor is used to perceive evaluated objects so as to get the membership of ranking fuzzy subsets $\left(R \mid u_{i}\right)$, so that fuzzy relation matrix can be obtained:

$$
R=\left[\begin{array}{cc}
R \mid & u_{1} \\
R \mid & u_{2} \\
\cdots \\
R \mid & u_{p}
\end{array}\right]=\left[\begin{array}{cccc}
r_{11} & r_{12} & \cdots & r_{1 m} \\
r_{21} & r_{22} & \cdots & r_{2 m} \\
\cdots & \cdots & \cdots & \cdots \\
r_{p 1} & r_{p 2} & \cdots & r_{p m}
\end{array}\right]_{p}
$$

Formula (4.1)

Element ${ }^{r_{i j}}$ in line ${ }^{i}$, column $j$ in the matrix $R$ is the membership of ${ }^{v_{j}}$ to ranking fuzzy subset of a certain evaluated objects from the perspective of element $u_{i}$. One evaluated object presents its performance in the aspect of element $u_{i}$ through the fuzzy vectors $\left(R \mid u_{i}\right)=\left(r_{i 1}, r_{i 2}, \cdots \cdots, r_{i m}\right)$, while in other evaluation methods, it is usually presented by a determined index value, therefore, from this perspective, fuzzy comprehensive evaluation method has a greater demand forinformation 
4) Determine the weight vector of evaluationfactors

Determine the weight vector of evaluationfactors: $A=\left(a_{1}, a_{2}, \cdots \cdots, a_{p}\right)$, wherein, element $a_{i}$ in the weight vector $A$ is the membership of element $u_{i}$ to fuzzy subsets. When deciding the relative importance of the evaluation indicators, AHP can be used; and then determine the weights and conduct normalization before synthesis, namely:

$$
\sum_{i=1}^{p} a_{i}=1 \quad a_{i} \geq 0 \quad i=1,2, \cdots \cdots, n .
$$

5) Result vector of synthesized fuzzy comprehensive evaluation

Synthesize the $R$ being evaluated and appropriate operator $A$, and we can get the result vector of fuzzy comprehensive evaluation for each evaluation object $\mathrm{P}$ :

$$
\begin{aligned}
& R=\left[\begin{array}{cccc}
\boldsymbol{r}_{11} & \boldsymbol{r}_{12} & \cdots & \boldsymbol{r}_{1 n} \\
\boldsymbol{r}_{21} & \boldsymbol{r}_{22} & \cdots & \boldsymbol{r}_{2 n} \\
\cdots & \cdots & \cdots & \cdots \\
\boldsymbol{r}_{m 1} & \boldsymbol{r}_{m 2} & \cdots & \boldsymbol{r}_{m n}
\end{array}\right] \\
& P=A * R=\left(\begin{array}{llll}
P_{1}, & P_{2} & \ldots & P_{n}
\end{array}\right)
\end{aligned}
$$

If, $P_{1}+P_{2}+\ldots+P_{n} \neq 1$, the normalization process can be used. $P_{1}$ is calculated from the row $j_{\text {in }} A$ and $R$, namely, $P_{1}$ is the membership of evaluated objects to ranking fuzzy subset $v_{j}$ on the whole.

6) Analyze the result vector of fuzzy comprehensive evaluation

In practice, the principle of maximum membership is the most common method, but in some special cases, this approachhas some flaws and loses a lot of information, and even gets unreasonable results. For multiple evaluated objects, weighted average can be used to calculate the membership rank of objects being evaluated, sorting according to their rank position.

\section{Comparison and evaluation}

1) Delphi method.The score given by five experts provides the single factor evaluation model concerning factor subsets; if illustrated by A, the first layer of index evaluation matrix isas follows:

$$
\begin{aligned}
& R_{1}=\left[\begin{array}{lllc}
0.1 & 0.3 & 0.4 & 0.2 \\
0.4 & 0.5 & 0.1 & 0 \\
0.1 & 0.1 & 0.5 & 0.3
\end{array}\right] \\
& R_{2}=\left[\begin{array}{lllc}
0.6 & 0.3 & 0.1 & 0 \\
0.5 & 0.3 & 0.1 & 0.1
\end{array}\right]
\end{aligned}
$$

$$
\begin{aligned}
R_{3} & =\left[\begin{array}{lllc}
0.3 & 0.4 & 0.2 & 0.1 \\
0.5 & 0.4 & 0.1 & 0 \\
0.1 & 0.2 & 0.3 & 0.4 \\
0.2 & 0.2 & 0.45 & 0.15
\end{array}\right] \\
R_{4} & =\left[\begin{array}{cccc}
0.2 & 0.4 & 0.3 & 0.1 \\
0.3 & 0.25 & 0.3 & 0.15 \\
0.3 & 0.5 & 0.1 & 0.1
\end{array}\right]
\end{aligned}
$$

2) Comprehensive evaluation model with determining the level.Determine the one-level fuzzy comprehensive evaluation model of $\mathrm{Cj}$ and one-level comprehensive evaluation model can be obtained by the respective weights.

$$
\begin{aligned}
& P_{1}^{(1)}=A_{1} * R_{1}=\left[\begin{array}{llll}
0.149 & 0.2733 & 0.3807 & 0.197
\end{array}\right] \\
& P_{2}^{(2)}=A_{2} * R_{2}=\left[\begin{array}{llll}
0.5875 & 0.3 & 0.1 & 0.0125
\end{array}\right] \\
& P_{3}^{(3)}=A_{3} * R_{3}=\left[\begin{array}{llll}
0.314 & 0.3489 & 0.2122 & 0.125
\end{array}\right] \\
& P_{4}^{(4)}=A_{4} * R_{4}=\left[\begin{array}{llll}
0.2878 & 0.4079 & 0.1883 & 0.116
\end{array}\right]
\end{aligned}
$$

3) The model to determine two-level comprehensive evaluation. According to the results of the previous onelevel evaluation, $\mathrm{Bj}$, the factor set of two-level comprehensive evaluation can be calculated, so that single factor evaluation matrix can be determined.

$$
\begin{aligned}
& R^{(2)}=\left[\begin{array}{cccc}
0.149 & 0.2733 & 0.3807 & 0.197 \\
0.5875 & 0.3 & 0.1 & 0.0125 \\
0.314 & 0.3489 & 0.2122 & 0.125 \\
0.2878 & 0.4079 & 0.1883 & 0.116
\end{array}\right] \\
& P^{(2)}=A^{(2)} * R^{(2)}=\left[\begin{array}{llll}
0.3104 & 0.3057 & 0.2575 & 0.1265
\end{array}\right]
\end{aligned}
$$

4) Make use of arithmetic scoring method to score and calculate the ranking:

$\mathrm{F} 1=100, \mathrm{~F} 2=75, \mathrm{~F} 3=50, \mathrm{~F} 4=25$, by the equation $\mathrm{Z}$ $=\mathrm{P} \cdot \mathrm{F}$, the comprehensive evaluation score is calculated as: $\mathrm{ZA}=70.5$. Similarly, we can get $\mathrm{ZB}=75.9, \mathrm{ZC}=77.7$, $\mathrm{ZD}=68.3$ and $\mathrm{ZE}=55.3$, and the final conclusion is to outsource the logistics service to $\mathrm{C}$ and late reserve ones are $\mathrm{A}$ and $\mathrm{B}$.

\section{CONCLUSION}

Through extensive literature searches, this paper combines empirical study and normative research to conduct process analysis, statistical analysis and case studies and explores how logistics outsourcing chooses partners. From this perspective, this paper focuses on the comprehensive evaluation index system to partners and establishes the associated theory and mathematical models for comprehensive evaluation .

The rapid development of China's economy makes competition more and more intense. The primary issue in corporate strategy development process should be how to strengthen and maintain the core competitiveness of the enterprise itself.After entering China, logistics outsourcing has gained a rapid development; enterprises start to realize the essential rolelogistics outsourcing when focusing on 
the development of core competitiveness and integrating enterprise resources. There is a big difference between traditional business relationships and outsourcing partnerships, which includes the difference in the way of cooperation, but the more difference presents in the degree of capacity complementary demand. Only with highquality cooperative activities can the strategic objectives of both sides be able to be achieved, so the selection of partners is very importantin the outsourcingcooperation process.

Finally, the article described the application of fuzzy comprehensive evaluation model in the outsourcing partner selection. By introducing actual cases, it illustratesthe practical operability of the model, which has provided some new methods and choices for enterprises to make decisions in the choice of partners. The results of calculation shows that the model can help enterprises find their desired subcontractorsbetter, making risks of cooperating withsubcontractors reduce and their core competitiveness improved.

\section{REFERENCES}

[1] Marasco A Third-party logistics;. A literature review [J] International Jonmal ofProduction Economics, 2008.

[2] YuT.An examination of the nature of trust in logistics outsourcing relationship, Empirical evidence from china $[\mathrm{J}]$. Industrial management \& Data systems, 2008.

[3] Zhou Lihua. Study on service quality evaluation indexof thirdparty logisticsbased on carno model[J], New Silk Road Horizon, 2008.

[4] Ma Lina, Studies on risk identification and control oflogistics outsourcing[D], Harbin Institute of Technology, 2011.

[5] Xu Minxiang. Study on enterprise logistics outsourcing partner choice evaluation index system.Management Science Digest, 2007

[6] Wang Hao, Lan Zhendong, Ge Honglei. Studies onport logistics outsourcing business model and development in the Yangtze River Delta region, 2011 